\title{
CERRADOS AMAZÔNICOS: FÓSSEIS VIVOS? ALGUMAS REFLEXÕES
}

\author{
Arnaldo CARNEIRO FILHO
}

\author{
RESUMO
}

\begin{abstract}
Como noutras regiões sul-americanas, mosaicos floresta-cerrado são também comuns na Amazônia, cobrindo extensas áreas. Permanecem inexplicadas as possíveis causas associadas à origem e distribuição destes tipos vegetais. Argumentos como fogo, oligotrofismo, alumínio, toxicidade e dinâmica de água nos solos foram amplamente utilizados como geradores de ambientes de cerrado. Da mesma forma os efeitos paleoclimáticos foram também considerados. Já é deveras conhecido o fato de que as mudanças climáticas, ocorridas ao longo do Quaternário, promoveram da mesma forma alterações nos tecidos ecológicos. Biogeógrafos têm acumulado evidências sobre os cenários atuais e pretéritos na Amazônia, corroborando o fato de que floresta e cerrado disputaram os espaços geográficos, por ocasião das mudanças climáticas. O presente estudo pretende incrementar a hipótese paleoclimática, através do estudo dos solos e paisagem. Parece evidente que a distribuição de floresta e cerrado em Roraima não possui qualquer correlação com aspectos físico-químicos dos solos e paisagem. Ademais, diversas feições, herdadas e todavia registradas nos solos e paisagem, tornam a situação ainda mais intrigante: (1) couraças lateríticas em diversos compartimentos da paisagem; (2) superfícies erosivas, recobertas por pavimento de laterita e quartzo leitoso, recobrindo tanto os solos sob cerrado como sob floresta; (3) perfis poligenéticos marcados por linhas de pedra e (4) solos similares sob floresta e cerrado. A presente distribuição de cada um dos citados elementos permite identificar duas situações: a) floresta atualmente ocupando antigos espaços de cerrado e b) cerrados ocupando espaços outrora recobertos por florestas.
\end{abstract}

\section{ABSTRACT}

Mosaics of forest and savannas are common in Amazonia, as in other parts of South America. They vary in physiognomy, complexity and shape of distribution, and their origin is still a matter of debate. Edaphic, climatic and hydrological factors, as well as fire, have been suggested. A further explanation involves paleoclimatic changes; shifting climatic belts, would have induced natural replacement of savanna and forest. The present study adds pedological and geomorphologic evidence in favour of the hypothesis.

The area of study is the Brasilian state of Roraima, where the mosaics have an apparently random distribution, uncorrelated to environmental aspects. The presence in such areas of (1) several levels of groundwater ironstone, (2) erosional surfaces covered by ironstone fragments and by pebbles of milky quartz, both under forest and savanna, (3) polycyclic profiles with stonelines and (4) both vegetation types in similar types of soil and relief, all indicate the former occurence of forests in present savanna areas, and vice-versa.

\section{INTRODUÇÃO}

O presente estudo tem lugar num dos diversos ecotones presentes na Amazônia, onde floresta se transforma de forma abrupta em vegetação de cerrado. Cerrados na Amazônia são formas vegetais relativamente minoritárias, porém ocorrentes e cobrindo extensas áreas, em padrões de distribuição tanto do tipo ilhas isoladas, como de maneira contínua (áreas 5 e 3 respectivamente). Concentraremos nossas atenções nas áreas de cerrado situadas em Roraima (área 5).
A denominação de cerrados foi aqui emprestada de HUBER (1982): "Savana ou campo são áreas com vegetação xeromórfica, formados por um extrato vegetacional, que consiste principalmente de gramíneas e ciperáceas, com ou sem extrato arbóreo e arbustivo, ambos formando camadas contínuas ou ocorrendo em grupos ou isolados". Mais precisamente estaremos nos referindo aos chamados cerrados Curatella (referência à forte presença da espécie Curatella americana). Em Roraima tais formações abertas são chamadas de lavrado. 


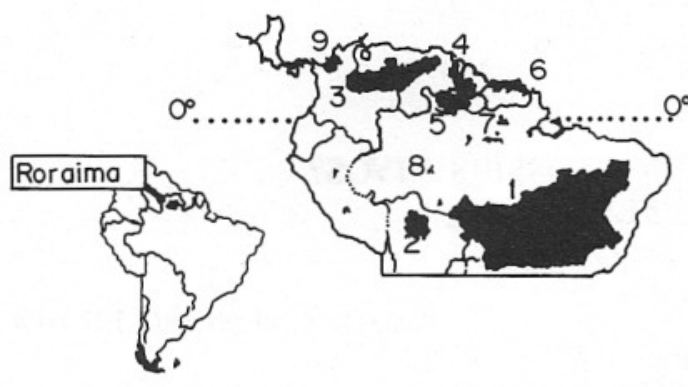

FIGURA 1 - Mapa de localização; áreas de cerrado intra e extra-amazônicas (de SARMIENTO, 1984 e PIRES, 1985). 1 - Cerrado do Planalto Central, 2 - Llanos de Moxo, 3 - Llanos do Orenoco, 4 - Gran Savana, 5 - Cerrados Roraima - Rupununi, 6 - Cerrados Costeiros, 7 - Campos amazônicos, 8 - Campos de $\mathrm{Hu}$ maitá e 9 - Llanos de Madalena.

Ocorrência e origem destes tipos de ecotone floresta-cerrado são ainda alvo de fartas discussões. Adaptação ao fogo, influência humana, oligotrofismo, controle climático e/ou hidrológico, são alguns dos argumentos utilizados para explicar a presença de tais mosaicos. Uma outra possível explicação poderia advir da relação destes mosaicos vegetais com condições paleoambientais. Seria como enfatizar os paleoclimas, originando o mosaico atual de floresta e cerrados, enquanto que os outros fatores anteriormente citados agiriam mais como mantenedores ou modificadores das áreas de cerrado, mas não como formadores.

Já é deveras conhecido que mudanças climáticas ocorridas durante o Quaternário tiveram im- portante papel, estimulando mudanças nos tecidos ecológicos. O cinturão tropical experimentou sucessivas alternâncias de períodos úmidos e secos, correlacionados respectivamente aos períodos interglacial e glacial das regiões de alta latitude e/ou altitude. Evidências destas alternâncias climáticas provêm de diversos domínios do conhecimento. A "teoria dos refúgios" poderia ser considerada uma primeira aproximação no sentido de determinar os paleoespaços bióticos, fornecendo inclusive indícios de pré-ocupação de florestas, cerrados e fauna associada (HAFFER, 1969; VANZOLINI \& WILLIAMS, 1970; PRANCE, 1973; BROWN \& AB'SABER, 1977; AB'SABER, 1982 e GRANVILLE, 1982), apesar da desproporção entre os escassos dados até então coletados e as dimensões geográficas para os quais são utilizados (NELSON, 1989).

Os padrões atuais de distribuição de vegetação podem ser resultado da interação entre paleoclimas e fatores ecológicos atuais. Melhor dizendo, nós deveríamos considerar a biogeografia atual como mera questão "tempo-espaço", ou seja, as condições paleoambientais foram as responsáveis pela origem e transformação destes tipos vegetais. A fitogeografia atual seria apenas um intervalo ou alguma forma de equilíbrio dinâmico, onde floresta e cèrrado respondem à presente condição ecológica.

Na Amazônia, os cerrados existentes, apesar das enormes distâncias que os separam, guardam uma intrigante similaridade florística, o que por si só argumentaria em favor da idéia de tais

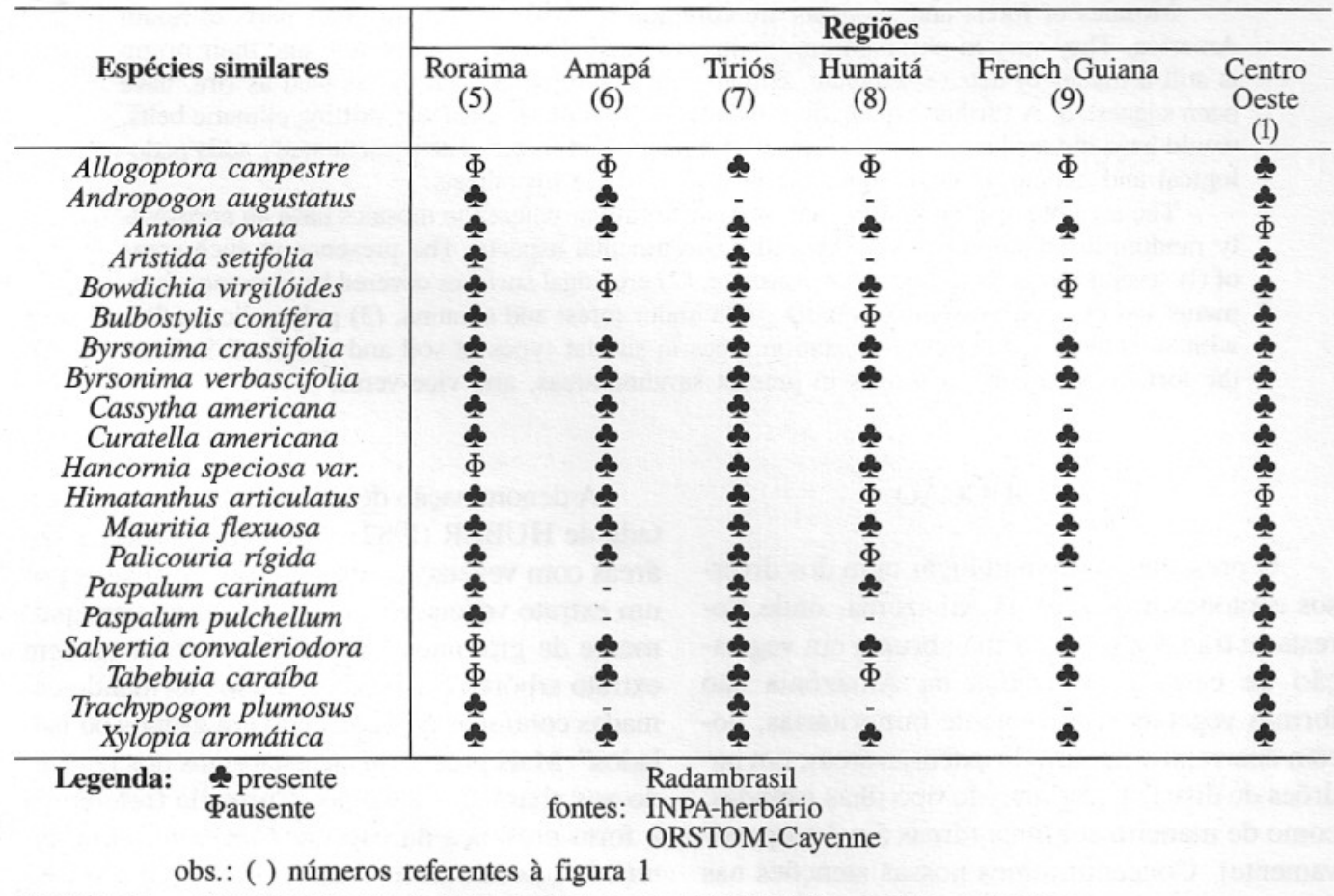

FIGURA 2 - Distribuição de algumas espécies nos cerrados intra e extra-amazônicos. 
cerrados representarem relitos botânicos. Ademais, a ausência de qualquer mecanismo ecológico originando tal distribuição poderia reforçar a idéia de uma origem paleoclimática (SASTRE, 1976).

GRANVILLE (1982), estudando a vegetação de cerrados costeiros na Guiana Francesa, observou uma total ausência de espécies endêmicas. $\mathrm{O}$ autor atribui tal fato à recente origem destes cerrados costeiros, não permitindo ainda a ação dos mecanismos de diferenciação e especiação. Baseado na paleopalinologia da região do Rupununi (Figura 1), EDEN (1964) já sugeria que os cerrados existiram fartamente na região até o último período glacial (12.000 B.P.). Após este período, a floresta decídua estendeu-se pela região, como resultado das condições climáticas que imperaram no Pleistoceno Superior.

Na África, PELTRE (1977) observou que os fragmentos florestais da Costa do Marfim estão atualmente ganhando espaço sobre os cerrados a uma taxa de aproximadamente 1 metro/ano. Semelhante expansão foi observada por FORESTA (1989), estudando zonas de contato florestacerrado no Congo, aonde inúmeras espécies florestais pioneiras ocorrem ao longo da frente de expansão. Na Amazônia, a atividade antrópica nestas zonas de contato muitas vezes dificulta qualquer observação sobre a dinâmica destes tecidos vegetais.

A observação da evolução solo-paisagem em Roraima pode trazer alguns novos elementos na remontagem dos paleocenários (AB'SABER, 1987). Alguns estudos levados a efeito em Roraima (CARNEIRO FILHO, 1991) permitiram observar que a distribuição floresta-cerrado não obedece a qualquer correlação com os solos e o relevo local (Figura 3). Paisagens cuja origem estaria associada a climas mais secos e não florestados, como os "chãos pedregosos",
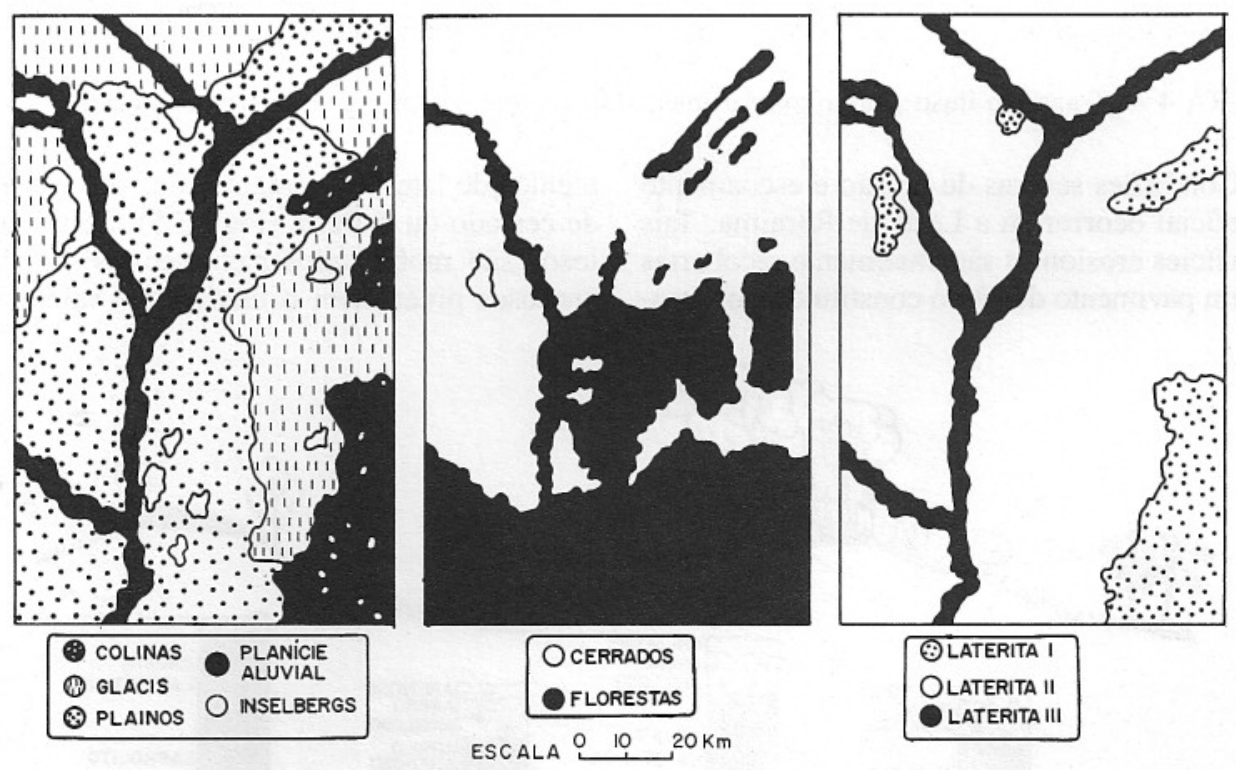

FIGURA 3 - Mapas temáticos de geomorfologia, vegetação e níveis de laterita (obtidos por interpretação de imagens Landsat-TM).

encontram-se hoje recobertas tanto por floresta como por cerrado.

Poderíamos assumir que sob diferentes coberturas vegetais como também diferentes condições climáticas, a fisiologia da paisagem funciona de maneira diferente com relação aos processos de erosão, pedogênese, escoamento e carga sólida fluvial. Conseqüentemente, nas áreas que serviram de cenário às mudanças climáticas pretéritas, deveríamos encontrar paisagens policíclicas como seqüências de terraços e glacis. Solos poligenéticos com linhas de pedra e paleossolos, superfícies decapitadas e níveis de laterita seriam outras formas ocorrentes.
Níveis de laterita podem ser considerados como formas relituais importantes, pois, em se tratando de formações originadas numa escala de tempo geológica, teriam a possibilidade de registrar condições climáticas pretéritas. Poderíamos sintetizar a formação das lateritas, como sendo um mecanismo de segregação de $\mathrm{Fe}$, que ocorre em ambiente anaeróbico e redutor: solos mal drenados dos ambientes sazonalmente inundados de mata-galeria ou ainda ao nível do lençol freático sob cobertura florestal, considerando que nestas condições o Fe é um elemento instável e normalmente mobilizado pelos ácidos orgânicos (GOUDIE, 1973). Florestas certamente 
inibem o concrecionamento posterior das lateritas, uma vez que preservam condições de umidade no subsolo (NAHON, 1986). O subseqüente concrecionamento deve ocorrer em condições climáticas diferentes, associado a uma mudança climática e conseqüentes mudanças na cobertura vegetal de floresta para cerrado.

Em Roraima ocorrem três níveis de laterita, cada um deles associado a um compartimento de paisagem (Figura 3). Estes níveis poderiam estar rela- cionados com seqüências de períodos: (1) úmidos e florestados, aonde se dariam os processos de segregação de $\mathrm{Fe}$ e (2) secos e cerrados, que seriam fases de concrecionamento, motivados por mudanças de nível freático e erosional, originando lateritas e superfícies de aplainamento nas colinas, glacis e terraços. Estas lateritas ocorrem em vertentes de drenagem superior à 3 a ordem (STRAHLER, 1952) e sua disposição na vertente parece associarse a antigos níveis freáticos (Figura 4).

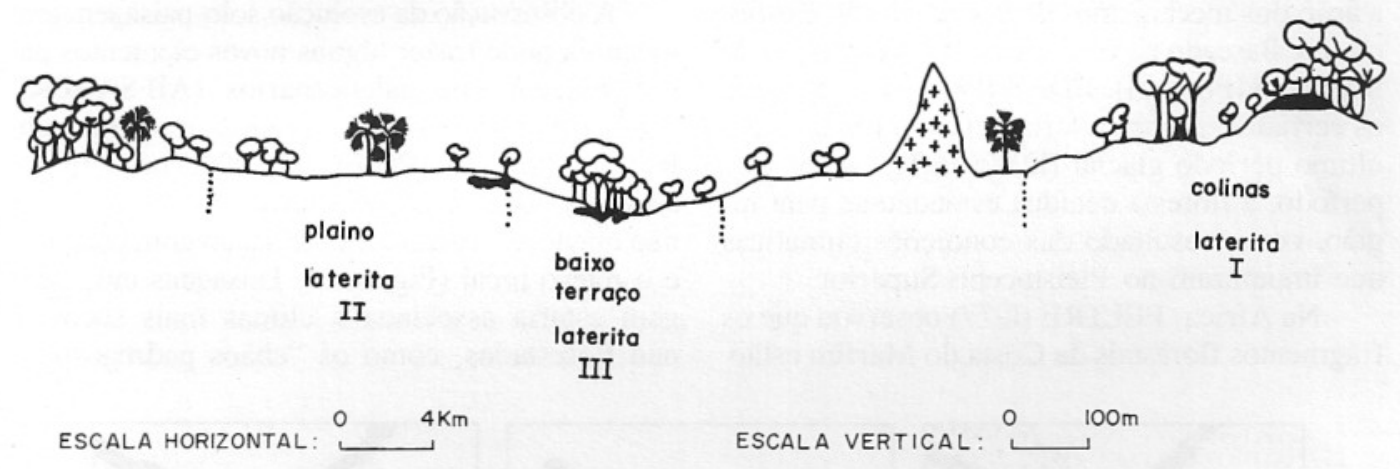

FIGURA 4 - Transecto ilustrando a compartimentação do relevo e níveis de laterita associados.

Condições severas de erosão e escoamento superficial ocorreram a Leste de Roraima. Tais superfícies erosionais são atualmente recobertas por um pavimento detrítico constituído por frag- mentos de laterita desmantelada, sob vegetação de cerrado ou floresta (Figura 5). Seixos angulosos são mobilizados nas encostas; depósitos arenosos preenchem o fundos dos vales.

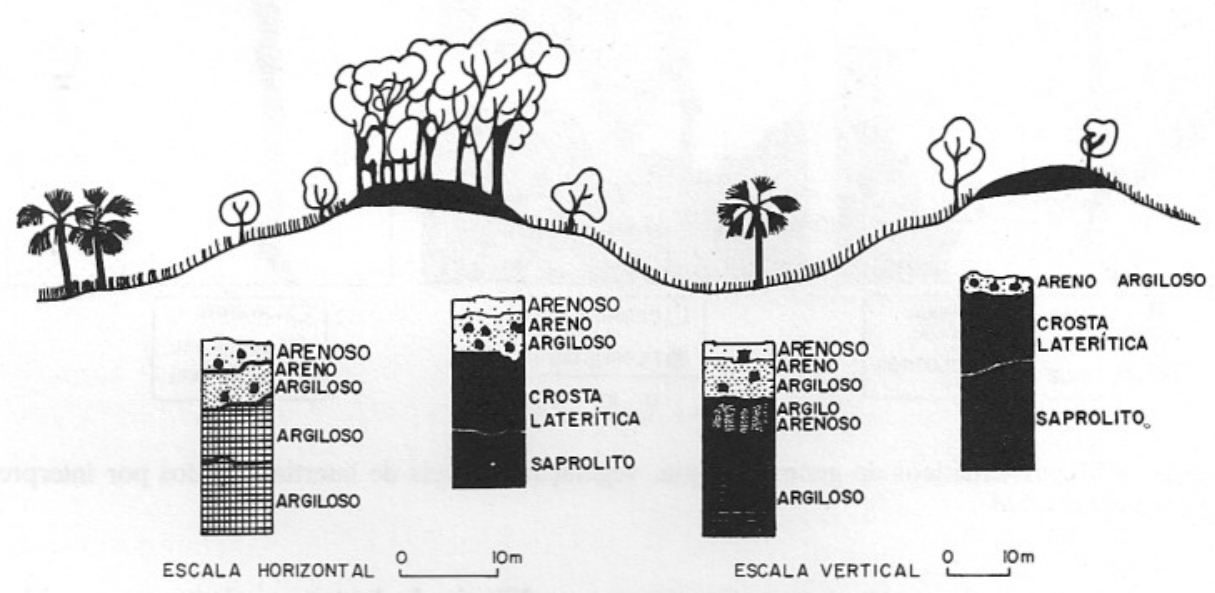

FIGURA 5 - Ocorrências de laterita na região colinosa, sob floresta e cerrado.

Os cerrados foram por muito tempo considerados como formações vegetais de natureza oligotrófica. A hipótese de algum aspecto edáfico no controle da distribuição floresta-cerrado em Roraima também foi considerada. O estoque de nutrientes de 13 perfis selecionados mostrou diferenças insignificantes para explicar a presente distribuição vegetal (Figura 6). Nalgumas áreas sob floresta o estoque de nutrientes mostrou-se ainda inferior ao dos solos sob cerrado.
Uma série de outras evidências adicionais ocorre em Roraima. Manchas de vegetação semi-árida com ao menos duas espécies de cactos (Melanocactus sp. e Cereus jamacaru) estão presentes em ambos os ambientes de floresta e cerrado. Nas áreas florestais eles ocorrem associados a morros-testemunhos ou afloramentos rochosos, enquanto que nos cerrados eles ocorrem dispersos nos solos arenoquartzosos. 


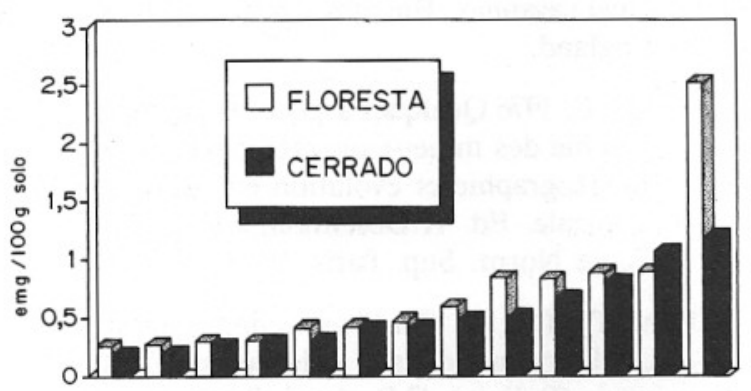

FIGURA 6 - Saturação de bases $(\mathrm{Ca}+\mathrm{Mg}+\mathrm{K}+\mathrm{Na})$ de 13 perfis selecionados.

Considerando os fatos anteriores e as sugestões de que tais situações são homólogas às que ocorrem em ambientes de sazonalidade acentuada ou semi-áridos (TRICART, 1974; BROWN \& AB'SABER, 1977), poderíamos nos referir à presente situação paisagística de Roraima como resultante de trabalho morfoclimático, associado às expansões e retrações de floresta e cerrado. Talvez as últimas mudanças espaciais nas fronteiras floresta-cerrado estejam associadas com os períodos secos 6.000 B.P. (SOUBIES, 1979/1980; SALDARRIAGA, 1986) ou 5.000-7.000 B.P. e 1.400-3.400 B.P. (SERVANT, 1981).

As hipóteses que estabelecem que a vegetação amazônica atual estaria numa situação de equilíbrio ou noutras palavras em "steady state" com as condições ambientais atuais, parecem insuficientes para explicar o presente mosaico de floresta-cerrado em Roraima. Parece evidente que a distribuição de floresta e cerrado não pode ser explicada exclusivamente a partir de fatores ecológicos atuais.

Em concordância com PRANCE (1982) e GRANVILLE (1982) estas áreas de cerrado podem ser consideradas como relitos modernos, originados durante as flutuações climáticas pleistocênicas e pós-pleistocênicas, fases associadas à penetração de climas secos na Amazônia. A acentuada similaridade florística e fisionômica destes cerrados amazônicos pode ser interpretada como isolamento recente, não permitindo ainda a formação de comunidades mais diversificadas. Assim sendo, processos de diferenciação e formação de novas associações de plantas nos cerrados da Amazônia estariam ocorrendo no presente.

\section{REFERÊNCIAS BIBLIOGRÁFICAS}

AB'SABER, A.N 1977 Espaços ocupados pela expansão dos climas secos na América do Sul, por ocasião dos períodos glaciais quaternários. Paleoclimas, no 3, Instituto de Geografia, USP; São Paulo.

1982 The paleoclimate and paleoecology of Brazilian Amazonia. In: Biological Diversification in the Tropics, Guillean T. Prance, Columbia University Press, N.Y., 41-59.

1987 Problemas paleoclimáticos e paleoecológicos de Roraima. Relatório de viagem depositado no Núcleo do INPA Roraima.

BROWN, K.S. \& AB'SABER,A.N. 1977 Centros de evolução, refúgios quaternários e conservação de patrimônios genéticos na região neotropical: Padrões de diferenciação em Ithomiinae (Lepdoptera: Nymphaiidae), Acta Amazonica 7(1):75-137.

CARNEIRO FILHO, A. 1991 Contribution to the study of the forest-savanna mosaic in the area of Roraima, Northern Amazon basin. Msc thesis at ITC, Enschede, Netherlands.

EDEN, M. 1964 The savanna ecosystem - northern Rupununi, British Guiana, McGill
University Savanna Research Project, Savanna Research Series, n. 1; Montreal.

FORESTA, H. 1989 Origine et évolution des savanes intramoyennes (R. P. Congo). II Apports de la botanique forestière. In: Paysages Quaternaires de l'Afrique Centrale, 326-335, ORSTOM, Paris.

GOUDIE, A. 1973 Duricrusts in Tropical and Subtropical Landscapes. Oxford Research Studies in Geography. Oxford University, London.

GRANVILLE, J.J. 1982 Rain forest and xeric flora refuges in French Guiana. In: Biological Diversification in the Tropics, Guillean T. Prance, Columbia University Press, N.Y., 159-181p.

HAFFER, J. 1969 Speciation in Amazonian Forest Birds.Science, vol.165, 131-137.

HUBER, O. 1982 Significance of Savanna Vegetation in the Amazon Territory of Venezuela. In: Biological Diversification in the Tropics, Guillean T. Prance, Columbia University Press, N.Y., 221-244.

NAHON, D.B. 1986 Evolution of iron crusts in Tropical Landscapes. In: Rates of chemi- 
cal weathering of rocks and minerals. Academic Press, New York.

NELSON, B.W. 1989 How reliable is the phytogeographical database for interpreting quaternary biogeography and paleoclimate of the Brazilian Amazon? International Symposium on Global Changes in South America during the Quaternary: Past - Present - Future. USP / São Paulo.

PELTRE, P. 1977 Héritage géomorphologique et paléoclimatique dans le tracé du contact forêtsavane, Le "V Baoulé" (Côte d'Ivoire Centrale). Travaux et Documents de l'ORSTOM, Paris.

PIRES, J.M. \& PRANCE, G.T. 1985 The Vegetation Types of the Brazilian Amazon. p. 109-145. In: Amazonia. Prance, G.T. \& Lovejoy, T.E. (ed.). Oxford, Pergamo Press.

PRANCE, G.T. 1973 Phytogeographic support for the theory of Pleistocene forest refuges in the Amazon Basin, based on evidence from distribution patterns in Caryocaraceae, Chrysobalanaceae, Dichapetalaceae and Lecythidaceae. Acta Amazonica 3(1):5-28.

1982 Forest refuges: Evidence from woody Angiosperms. In: Biological Diversification in the Tropics; Guillean T. Prance; Columbia University Press; N.Y., 137-157.

SALDARRIAGA, J. et al. 1986 Holocene fires in the Northern Amazon basin.Quaternary Research 26, 358-366.
SARMIENTO, G. 1984 The Ecology of Neotropical savannas. Harvard University Press, England.

SASTRE, C. 1976 Quelques aspects de phytogéographie des milieux ouverts guyanais. In: Biogéographie et évolution en Amérique tropicale. Ed. H.Descimon, Labo. Zool. École Norm. Sup. Paris, 9:67-74.

SERVANT, M. et al. 1981 Phases climatiques arides holocènes dans le sud-ouest de l'Amazonie (Bolivie). C.R. Acad. Sc. Paris, ser. II, t.292, 1295-97.

SOUBIES, F. 1979/1980 Existence d'une phase séche en Amazonie Brésilienne daté par la présence de charbons dans le sols (6000-3.000 ans B.P.). Cahier ORSTOM, sér. Geol., vol. XI, no 167, 133-148.

STRAHLER, A.N. 1952 Hypsometric (areaaltitude) analysis of erosional topography. Bulletin of the Geological Society of America 63 , p. 923-39.

TRICART, J. 1974 Existence de periodes sèches au Quaternaire en Amazonie et dans les régions voisines. Revue de Geomorphologie Dynamique. XXIII (4):145-158. Paris.

VANZOLINI P.E. \& WILLIAMS, E.E. 1970 South American anoles: geographic differentiation and evolution of the Anolis chrysolepis species group (Sauria, Iguanidae). Arq. Zool. São Paulo 19, 1-298.

Trabalho apresentado no "Simpósio Internacional do Quaternário da Amazônia” - Manaus, 8-13 de novembro de 1992.

Endereço do autor:

ARNALDO CARNEIRO FILHO - Instituto Nacional de Pesquisas da Amazônia - INPA - CEPEC - Caixa Postal 478 - 69011-970 - Manaus - AM. 